\title{
INTRODUCING THEORY LINKING GENESIS OF HAIR SHAFT BIPOLARITY WITH ARRECTOR PILI MUSCLE PROXIMAL ATTACHMENT
}

\author{
Abrahám A. Embí BS 1 (iD) \\ MBA, 13442 SW 102 Lane Miami, Florida 33186, USA
}

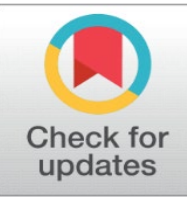

Received 16 October 2021

Accepted 16 November 2021

Published 30 November 2021

\section{CorrespondingAuthor}

Abrahám A. Embí, Embi21@att.net

DOI

10.29121/granthaalayah.v9.i11.2021 .4364

Funding: This research received no specific grant from any funding agency in the public, commercial, or not-for-profit sectors.

Copyright: (C) 2021 The Author(s). This is an open access article distributed under the terms of the Creative Commons Attribution License, which permits unrestricted use, distribution, and reproduction in any medium, provided the original author and source are credited.

\section{ABSTRACT}

\section{Definition of Terms}

APM = Arrector Pili Muscle. Muscle that attaches to the base of a hair follicle at one end and to skin on the other.

$\mathbf{K} 3 \mathbf{F e}=$ Acronym for Potassium Ferricyanide $\mathrm{K}_{3}\left[\mathrm{Fe}(\mathrm{CN})_{6}\right]$.

EMR = Electromagnetic Radiation

Hair Follicles Terminal Palisades Nervous Endings = Hairs are known as a sensory apparatus for touch. Their follicles are innervated predominantly by palisade endings composed of longitudinal and circumferential lanceolate endings. See reference Suzuki et al. (2012) for further details.

Previous publications described the presence of bipolarity or (+-) electrical charges in the human hair shaft, this due to an apparent segmental electromagnetic radiation Gap demonstrated by a total absence of precipitated Potassium Ferricyanide crystals. In this manuscript additional data is presented elucidating the genesis of said absence. The in vitro experiments showing a correlation between a segmental absence of longitudinal terminal palisades nervous endings prevalent in the rest of the outer membrane in the hair follicle anatomy this absence attributed to the arrector pili muscle (APM) proximal attachment site to the hair follicle. Due to their intrinsic metabolism, nerve cells do emit electromagnetic radiation; their absence not allowing for the positive $(+)$ charge of precipitated Potassium Ferricyanide crystals to reach one side of the shaft. In addition, it was concluded that there are two types of human hair images. The first by optical microscopy, the second a functional one obtained from electromagnetic radiation precipitating Ferricyanide crystals.

Keywords: Hair Follicle Gap, Bipolar Hair Shaft, Genesis Shaft Bipolarity Shepherds Hook Genesis, Hair Follicle Electromagnetism, Terminal Palisade Axons, Arrector Pili Muscle

\section{INTRODUCTION}

This manuscript could be described as a retrospective enhancement of two prior publications from this author. It entails a deeper view on the genesis of the human hair shaft bipolarity. The first publication had the words "curious observations", which is defined as the first step in a decision-making process; as published in the title; the hair shaft electrical bipolarity was added at the end of the paper as an afterthought Embi (2021). The second publication, the presence of an electromagnetic gap (GAP) in the outer sheath of the hair follicle was identified as a mechanism for the hair shaft electrical bipolarity (Figure 1), Embí (2021). In the present and third manuscript on the same topic, the genesis of the 
GAP is attributed and supported as resulting from a previously documented anatomical segmental absence of terminal nerve endings in the follicle (Figure 2), (Figure 3). This void or nerve endings could be attributed as consequence of the proximal anatomical attachment point of the arrector pili muscle (APM). The GAP as stated in Suzuki et al. (2012) "Most palisade endings had a gap in a circle of longitudinal lanceolate endings. The gap was $1 / 8-1 / 2$ of the circle and usually faced to the epidermis, that is, superficial side of the hair root which canted over to the skin surface". The term "palisade" is used to describe a layer of columnar nervous endings. Since the terminal nerve cells require energy for their functions Ashrafi and Ryan (2017) this energy would in turn be converted into electromagnetic radiation Scherlag et al. (2016).

\section{MATERIALS AND METHODS}

This manuscript is quoting and reproducing previously published images supporting the absence of terminal nerves endings in a segment of the hair follicle. This absence, in turn causes an abrupt cessation of electromagnetic radiation as shown in the attached image (Figure 3 plus video), which in turn does not allow for a positive $(+)$ charge to reach the hair shaft.

\section{FIGURES}

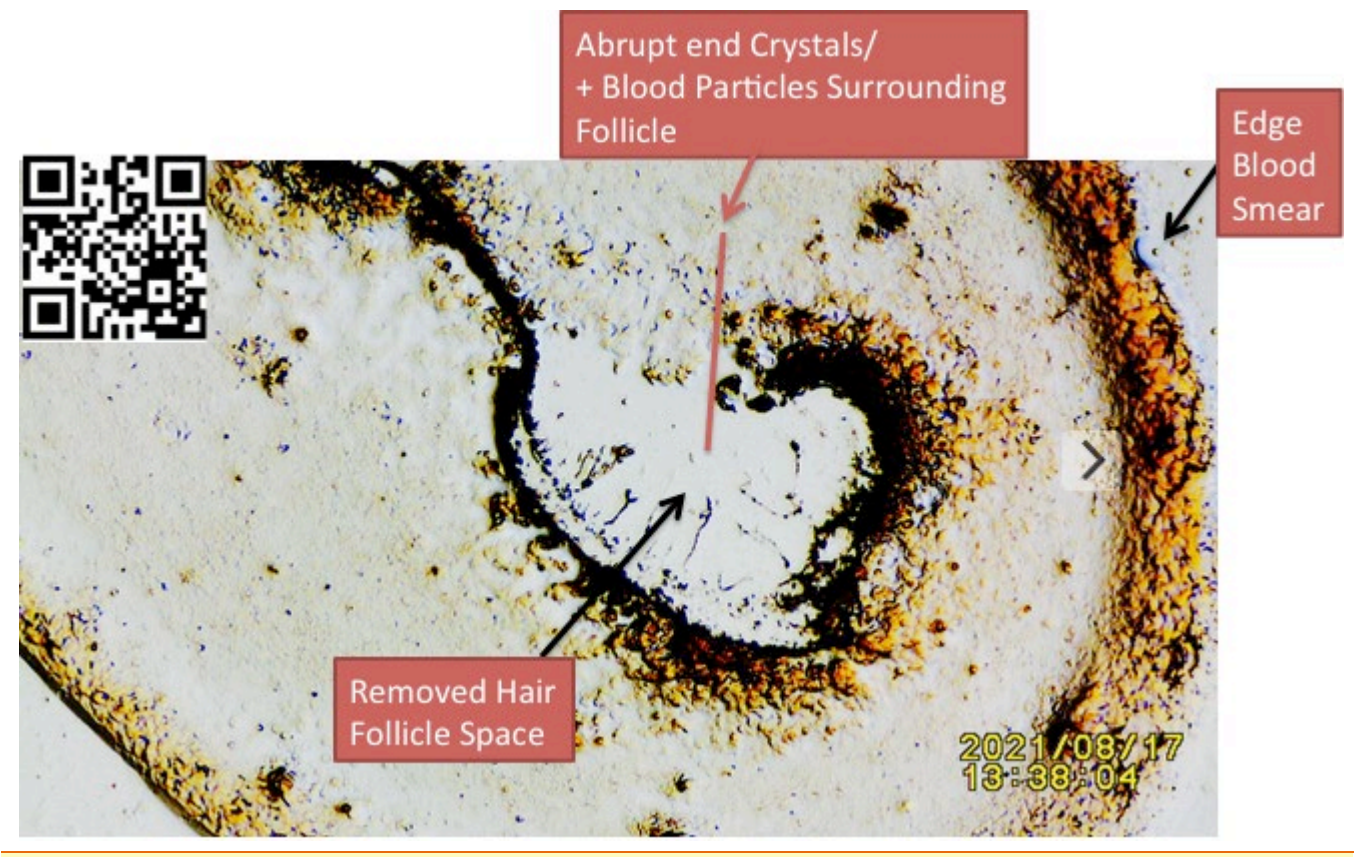

Figure 1 Hair outline after removal. SSP in drop of KFe3 in fresh blood smear, hair placed on KFe3 wet side and allowed to evaporate. Black Arrows: Pointing at mix of crystals and coagulated blood plus edge of blood smear.For details link to: https://youtu.be/LLz43yAbpg0.... or Scan QR Code in left upper corner of image.

Image duplicated from: Embí (2021). Introducing Gap in Hair Follicle Electromagnetism as Proposed Mechanism for The Presence of Bipolar Electrical Charges Inherent in The Human Hair Shaft. International Journal of Research - GRANTHAALAYAH, 9(9), 79-87. doi: 10.29121/granthaalayah. v9.i9.2021.4260

NOTE: SSP= Single Slide Preparation. Where material(s) placed of surface of glass slide 


\section{Confocal Microscopy Image of follicle GAP of Terminal Axons}

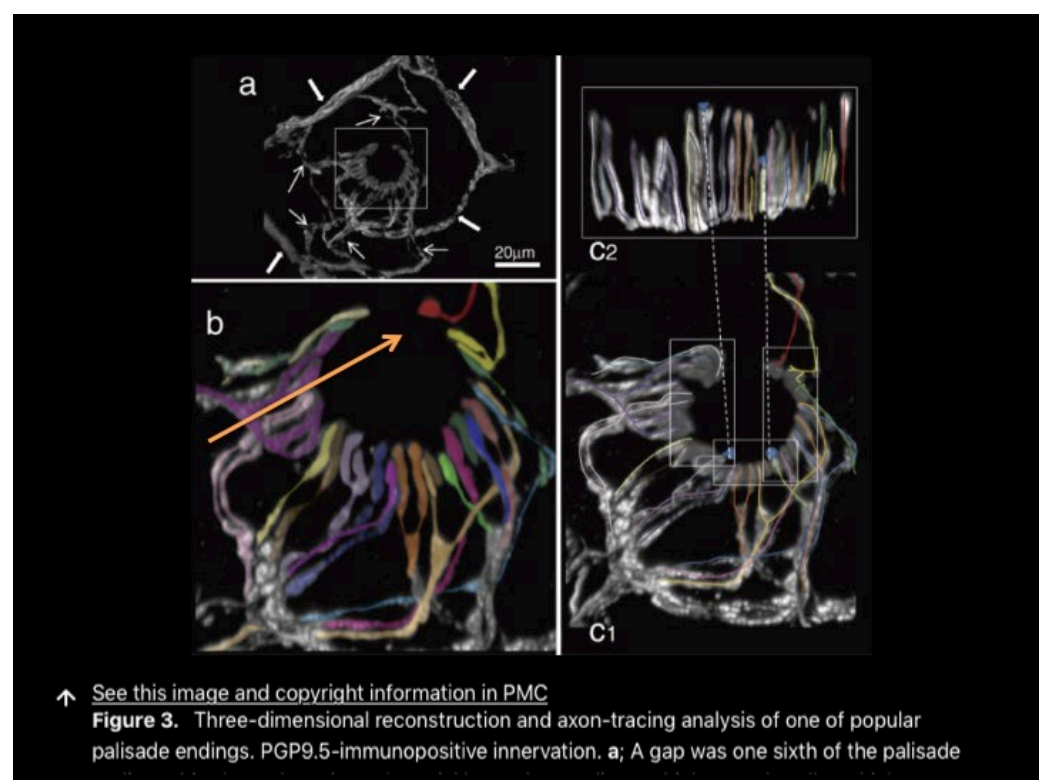

Figure 2 Orange Arrow (Mine): Pointing at palisade 'GAP" arrangement. Gap theorized in this manuscript as correlating with arrector pili proximal end. As stated in Suzuki et al. (2012) "Most palisade endings had a gap in a circle of longitudinal lanceolate endings. The gap was $1 / 8-1 / 2$ of the circle and usually faced to the epidermis, that is, superficial side of the hair root which canted over to the skin surface"

Image duplicated from Suzuki, M. et al. https://doi.org/10.2183/pjab.88.583. Suzuki et al. (2012). How many hair follicles are innervated by one afferent axon? A confocal microscopic analysis of palisade endings in the auricular skin of thy1-YFP transgenic mouse. Proceedings of the Japan Academy. Series B, Physical and Biological Sciences, 88, 583 - 595

\section{Human Hair Magnetic Outer Membrane Imprint from Palisades Longitudinal Terminal Nerve Endings Contrasting with Coventional Drawings Derived from Optical Microscopy}

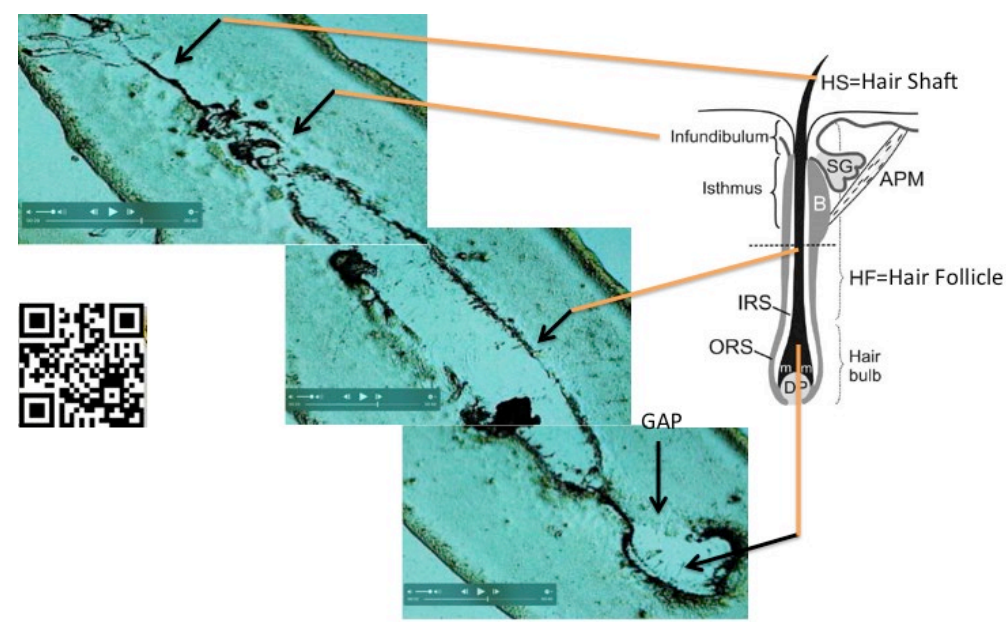

Figure 3 Cut and Paste frames to illustrate the human scalp hair magnetic imprint post hair removal from slide. Scalp hair in fresh blood smear mixed with liquid Potassium Ferricyanide, after drying, outer layers of hair are delineated showing:

Human hair magnetic Imprint on glass slide. Drawing on right side of figure reproduced as described in the copyright fair use doctrine.

Credit of drawing given to: Pisal Rishikaysh et al. DOI: doi:10.3390/ijms15011647 


\section{RESULTS AND DISCUSSION}

Numerous images obtained by this author, show that when the human hair is placed on a slide and covered by liquid Potassium Ferricyanide (K3Fe) there is an accumulation of $\mathrm{K} 3 \mathrm{Fe}$ crystals attracted to the outer layers of the shaft. This is due to the attraction of incoming electromagnetic radiation by $\mathrm{K} 3 \mathrm{Fe}$ Baranov et al. (2015), Figgis et al. (1969) . As documented in Figure 3 above (please scan QR Code) after removing the hair, a silhouette of the hair proper magnetic fields is displayed. Notice the GAP. The K3Fe positive (+) charge unable to reach one side of the hair shaft. Additionally, functional electromagnetic hair images are presented Figure 1, Figure 2, Figure 3. Of interest is their difference from artists drawings of pathologist slides with the electromagnetic imprints.

\section{MEDICAL IMPLICATIONS}

Further research is recommended to elucidate if there are electrical bipolarity changes in hair follicles diseases, such as Alopecia Areata and Telogen Effluvium amongst others. Published research has already documented aging as probable factor in decreasing the hair magnetic imprints as shown in the unpublished image below Figure 4.

Questions Arise: Would follicular diseases be identified by altered hair shaft bipolarities? ....Does the APM has a role in maintaining the follicular integrity and stability? ( Sinclair et al. (2015), Torkamani et al. (2014)).

Hair in Catagen (Old age prior to falling)

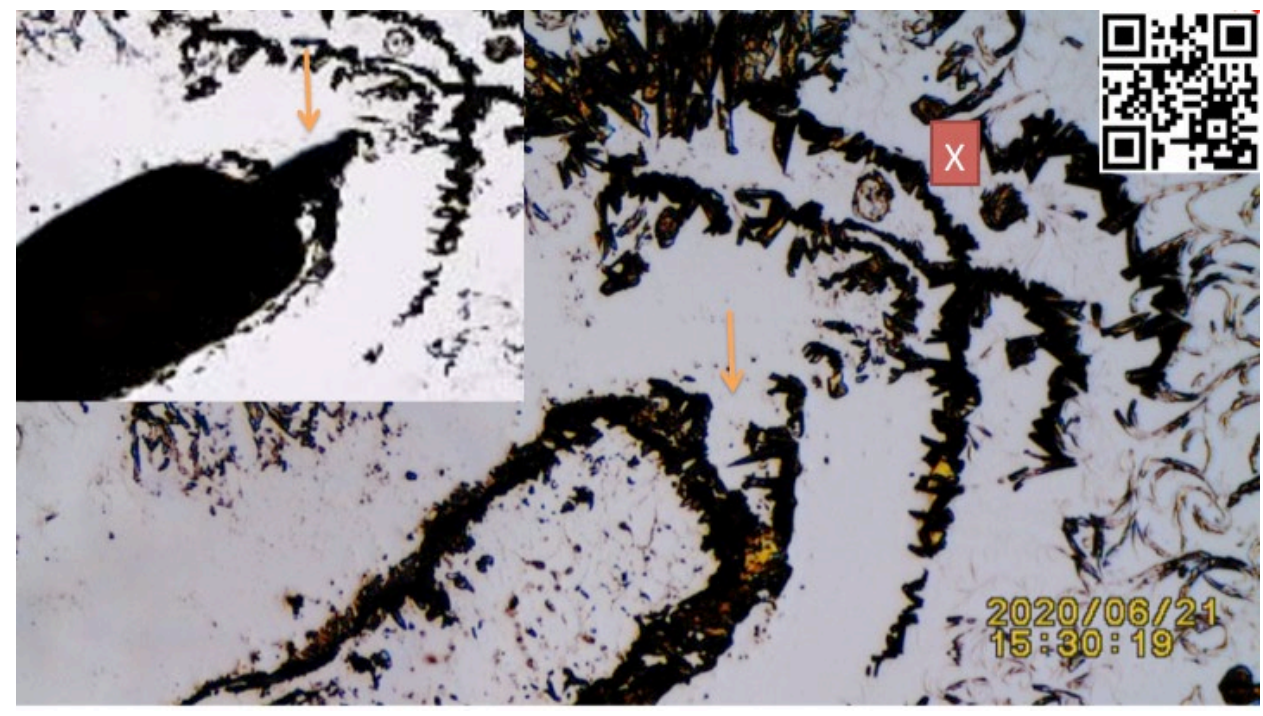

Figure 4 Unpublished image. Hair in Catagen stage (Old human scalp hair) prior to shedding in contact with liquid Potassium Ferricyanide (K3Fe) on glass slide. Orange Arrow pointing at:

Top left insert: Protruding dead tissue (typical of Catagen stage). Right side image showing $\mathrm{X}=$ Disorganized electromagnetic waves. Orange Arrow= Pointing at total absence of K3Fe crystals, indicating dead old tissue or absence of metabolism from palisade nerve endings.

For additional details please link to: https://youtu.be/A1zfUqUMoqk Or Scan QR Code in right upper corner of figure. 


\section{REFERENCES}

Ashrafi, G., \& Ryan, T.A. (2017). Glucose metabolism in nerve terminals. Current Opinion in Neurobiology, 45, 156-161. Retrieved from https://doi.org/10.1016/j.conb.2017.03.007

B. N. Figgis, Malcolm Gerloch, Ronald Mason, and Ronald Sydney Nyholm(1969) The crystallography and paramagnetic anisotropy of potassium ferricyanide. Retrieved from https://doi.org/10.1098/rspa.1969.0031

D. G. Baranov, J. H. Edgar, Tim Hoffman, Nabil Bassim, Joshua D. Caldwell. (2015) Perfect interferenceless absorption at infrared frequencies by a van der Waals crystal. Physical Review B, 2015; 92 (20) . Retrieved from https://doi.org/10.1103/PhysRevB.92.201405

Embi, AA (2021). Some curious findingshair follicles bioelectromagnetic radiation expressed as light displacing matter in its path and the contralateral emission of magnetic fields found in the hair shaft. International Journal of Research - GRANTHAALAYAH, 9(7), 334. Retrieved from https://doi.org/10.29121/granthaalayah.v9.i7.2021.4114

Embí, A. A. BS. (2021). Introducing Gap in Hair Follicle Electromagnetism as Proposed Mechanism for The Presence of Bipolar Electrical Charges Inherent in The Human Hair Shaft. International Journal of Research GRANTHAALAYAH, 9(9), 79-87. Retrieved from https://doi.org/10.29121/granthaalayah.v9.i9.2021.4260

Scherlag, B.J., Sahoo, K., Embi, A.A. (2016) A Novel and Simplified Method for Imaging the Electromagnetic Energy in Plant and Animal Tissue. Journal of Nanoscience and Nanoengineering 2(1): 6-9.

Suzuki M, Ebara S, Koike T, Tonomura S, Kumamoto K. (2012) How many hair follicles are innervated by one afferent axon? A confocal microscopic analysis of palisade endings in the auricular skin of thy1-YFP transgenic mouse. Proc Jpn Acad Ser B Phys Biol Sci.88(10):583-95. Retrieved from https://doi.org/10.2183/pjab.88.583

Sinclair R, Torkamani N, Jones L. (2015) Androgenetic alopecia: new insights into the pathogenesis and mechanism of hair loss. F1000Res. Aug 19;4(F1000 Faculty Rev):585. doi: 10.12688/f1000research.6401.1. PMID: 26339482; PMCID: $\quad$ PMC4544386. Retrieved from https://doi.org/10.12688/f1000research.6401.1

Torkamani N, Rufaut NW, Jones L, Sinclair RD. (2014) Beyond goosebumps: does the arrector pili muscle have a role in hair loss? Int J Trichology. Jul;6(3):88-94. doi: 10.4103/0974-7753.139077. PMID: 25210331; PMCID: PMC4158628. Retrieved from https://doi.org/10.4103/0974-7753.139077 